\title{
Entomopathogenic Rickia wasmannii fungal infection generated colony-level stress effects cause size decline in Myrmica ants
}

Sándor Cső́sz

Centre for Ecological Research

\section{Zoltán Rádai}

Centre for Ecological Research

András Tartally

University of Debrecen

\section{Lilla Erika Ballai}

University of Debrecen

Ferenc Báthori ( $\nabla$ ferenc.bathori@gmail.com )

Centre for Ecological Research

\section{Research Article}

Keywords: Rickia wasmannii, Myrmica ants, colony-level stress

Posted Date: March 17th, 2021

DOI: https://doi.org/10.21203/rs.3.rs-289400/v1

License: (c) (1) This work is licensed under a Creative Commons Attribution 4.0 International License. Read Full License

Version of Record: A version of this preprint was published at Scientific Reports on July 13th, 2021. See the published version at https://doi.org/10.1038/s41598-021-93583-0. 

cause size decline in Myrmica ants

Sándor Csősz ${ }^{1,2}$, Zoltán Rádai ${ }^{3}$, András Tartally $^{4}$, Lilla Erika Ballai ${ }^{4}$, Ferenc Báthori ${ }^{1,4}$

${ }^{1}$ Evolutionary Ecology Research Group, Institute of Ecology and Botany, Centre for Ecological Research, Alkotmány út 2-4, Vácrátót H-2163, Hungary; ferenc.bathori@gmail.com (F.B.); sandorcsosz2@gmail.com (S.C.)

${ }^{2}$ MTA-ELTE-MTM Ecology Research Group, Pázmány Péter sétány 1/C, Budapest H-1117, Hungary; sandorcsosz2@gmail.com

${ }^{3}$ Lendület Seed Ecology Research Group, Institute of Ecology and Botany, Centre for Ecological Research, Alkotmány út 2-4, Vácrátót H-2163, Hungary; zozi.web@ gmail.com

${ }^{4}$ Department of Evolutionary Zoology and Human Biology, University of Debrecen, Egyetem tér 1, Debrecen H-4032, Hungary; ballai.lilla@gmail.com

(L.E.B.); tartally.andras@science.unideb.hu (A.T.); ferenc.bathori@gmail.com (F.B.)

* Corresponding author: ferenc.bathori@gmail.com

Abstract

Parasitism-generated negative effects on ant societies are multifaceted, implying individual and colony-level responses. Though laboratory based evidence shows that the sublethal fungus Rickia wasmannii is responsible for physiological and behavioral responses that may negatively affect individual workers' resilience and life expectancy in Myrmica ant workers, colony-level stress response to this parasite is largely unknown. Here, we focus on understanding of a longterm, colony-level effect of Rickia infection on Myrmica scabrinodis ant populations by tracking trait size-based changes. We collected worker specimens from infected and uninfected colonies from the same population in order to: (i) compare body size in response to parasitism, (ii) assess the extent to which possible changes in size are associated with the severity of 
infection, and (iii) investigate shifts in body size in response to infection over time by testing correlation of workers' ages and sizes. We found that workers from infected colonies were significantly smaller than their healthy congeners, but neither infection level nor the age of the workers showed significant correlation with the size in infected colonies. Decreasing body sizes in infected colonies can be ascribed to workers' mediated stress toward developing larvae, which are unable to attain the average body size before they pupate.

\section{Introduction}

Ants (Hymenoptera: Formicidae), the most widespread social organisms on Earth, attract an amazing diversity of parasitic organisms, such as viruses ${ }^{[1]}$, bacteria ${ }^{[2]}$, fungi ${ }^{[3,4]}$, and an array of uni- and multicellular animal organisms ${ }^{[5,6]}$. Many of these parasites cause lethal diseases ${ }^{[7]}$, but most are sublethal, i.e. they do not necessarily pose an imminent danger, though they are assumed to have detrimental effects on the quality of the hosts' lives ${ }^{[4,8]}$.

Entomopathogenic fungus, Rickia wasmannii Cavara, 1899 (Ascomycota: Laboulbeniales) is a typical sublethal parasite of several Myrmica (Hymenoptera: Formicidae) species which has long been believed to have no detrimental effect on its host individuals ${ }^{[9,10,11]}$. For a century, very little was known about this parasitic organism, and only scant information was available on their distribution and host specificity ${ }^{[4,12,13]}$. The effect of the fungus on the physiology of its host species was largely unknown. In recent years, modern research has shed light on the real nature of this widespread organism and has shown that it has negative effects on individual host ants. Based on previous studies on the physiological response of infected workers of the main host Myrmica scabrinodis Nylander, 1846, infected workers show higher mortality under laboratory conditions ${ }^{[14,15]}$. Infected $M$. scabrinodis workers were also shown to exhibit improved sanitary behavior ${ }^{[14]}$ and a decreased level of intraspecific aggressivity ${ }^{[16,17]}$ which may be disadvantageous for the infected colonies in competitive interactions.

Although $R$. wasmannii is known to elicit different detrimental physiological responses in individual workers, colonies seem to resist and compensate for the negative effects of the infection; they contain queens, rear larvae and pupae, and all age-classes of workers are present (see Csata et al. ${ }^{[17]}$ ). This may be due to the fact that it is often challenging to study colonylevel effects of an infection under in situ conditions, particularly when complex environmental parameters and multifactorial relationships with a number of other organisms ${ }^{[8,15,18]}$ must be 
taken into consideration. This may be one of the reasons why a colony-level stress effect of Rickia fungal parasites has never been the subject of focused research.

We propose that the colony-level negative effect of the infection is detectable through the decline in size of colony workers. Here, we hypothesize that the infection has detrimental effects on the fitness of brood caring workers, making them unable to engage in foraging activity and feeding and grooming behavior toward their larvae to the necessary extent, and the declining larval growth rate ultimately leads to a decrease in the size of the next generation of workers. The size of the first workers infected is not affected, but $R$. wasmannii infection is transferred over generations, causing a long-term chronic, life-long infection in a colony, which is known to expand year by year in the nest with some level of seasonal fluctuation ${ }^{[19]}$. The detrimental colony-level effect of the infection accumulated over time can be measured in workers' sizes. We hypothesized that if $R$. wasmannii infection is widespread in an ant colony, it will detrimentally affect the size of workers groomed by infected sisters owing to the parental colony's reduced fitness. To test this hypothesis, we compared the sizes of randomly sampled workers from infected and uninfected colonies.

How can we rule out the possibility that the size decline is caused not by direct larval infection but by mediated colony-level stress among workers? Rickia wasmannii fungus is found to grow on imago ${ }^{[14,20]}$ and is not known to infect ant larvae ${ }^{[11,21]}$ but in order to make sure that a possible size decline is ascribed to stress mediated by nursing workers and is not caused by direct larval infections, trait scaling patterns were also observed. The background of this approach is that infections in the larval stage often cause scrambled trait combinations in adults [22] via altered static trait allometries. If significant shifts in trait scaling were detected in infected colonies, parasitism generated stress might not only be mediated by infected workers.

We also tested whether the extent of infection (i.e., number of thalli on the cuticular surface of the ants) and the workers' ages affect the detected changes in imaginal size. Therefore, we registered both infection level and estimated age of the workers in the colony.

Understanding the colony-level effect of R. wasmannii infection on Myrmica colonies in a natural environment would foster a better understanding of the dynamics of this enthomopathogenic fungus and the host-parasite system. This issue has interesting implications, because Myrmica ants are a known host species of a guild of ant guests and socially parasitic organisms which live together with their colonies ${ }^{[8,23]}$. This network is very 
sensitive, and every single component of this very complex system might have a regulatory role of its own.

\section{Results}

A total of 300 workers from 30 colonies were measured (15 colonies of each class). The calculated Intra Class Correlation between 16 pairs of repeated measures was very high $(\mathrm{R}=$ 0.980 to 1.0 ), i.e. measurement error was negligible. Body size was significantly decreased in infected colonies in comparison to uninfected ones $(\beta=-0.038, \mathrm{SE}=0.014, \mathrm{t}=-2.66, \mathrm{P}=0.013$, Fig. 1). We found no significant effect of age $(\beta=-0.003, \mathrm{SE}=0.005, \mathrm{t}=-0.65, \mathrm{P}=0.514)$ or thalli number $(\beta=0.0004, \mathrm{SE}=0.006, \mathrm{t}=0.06, \mathrm{P}=0.950$, Fig. 2$)$ on body size among infected colonies. Variance inflation factor was 1.025 for both independent variables, suggesting no substantial multicollinearity. Nevertheless, based on the Poisson GLMM, age had a significant positive effect on thalli number $(\beta=0.405, \mathrm{SE}=0.011, \mathrm{t}=35.71, \mathrm{P}<0.001$, Fig. 3$)$. Furthermore, we found no significant difference between trait correlation matrices of uninfected and infected colonies, indicating that they exhibit the same allometries $\left(\mathrm{X}^{2}=1.313, \mathrm{P}=0.999\right.$, Fig. 4). 


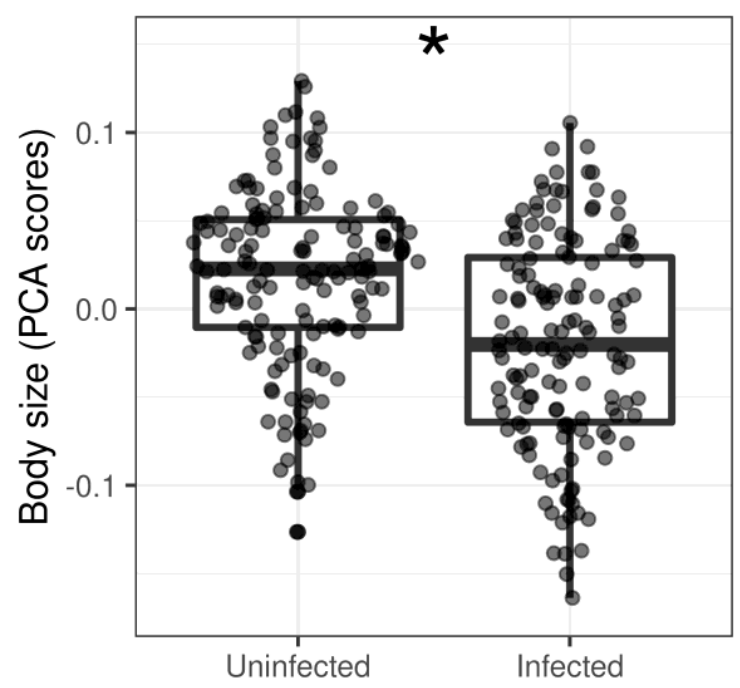

112

113

114

115

116

117

118

119

120

Fig. 1. Distribution of PCA axis values representing body size in uninfected and infected colonies. Asterisk marks statistically significant difference.
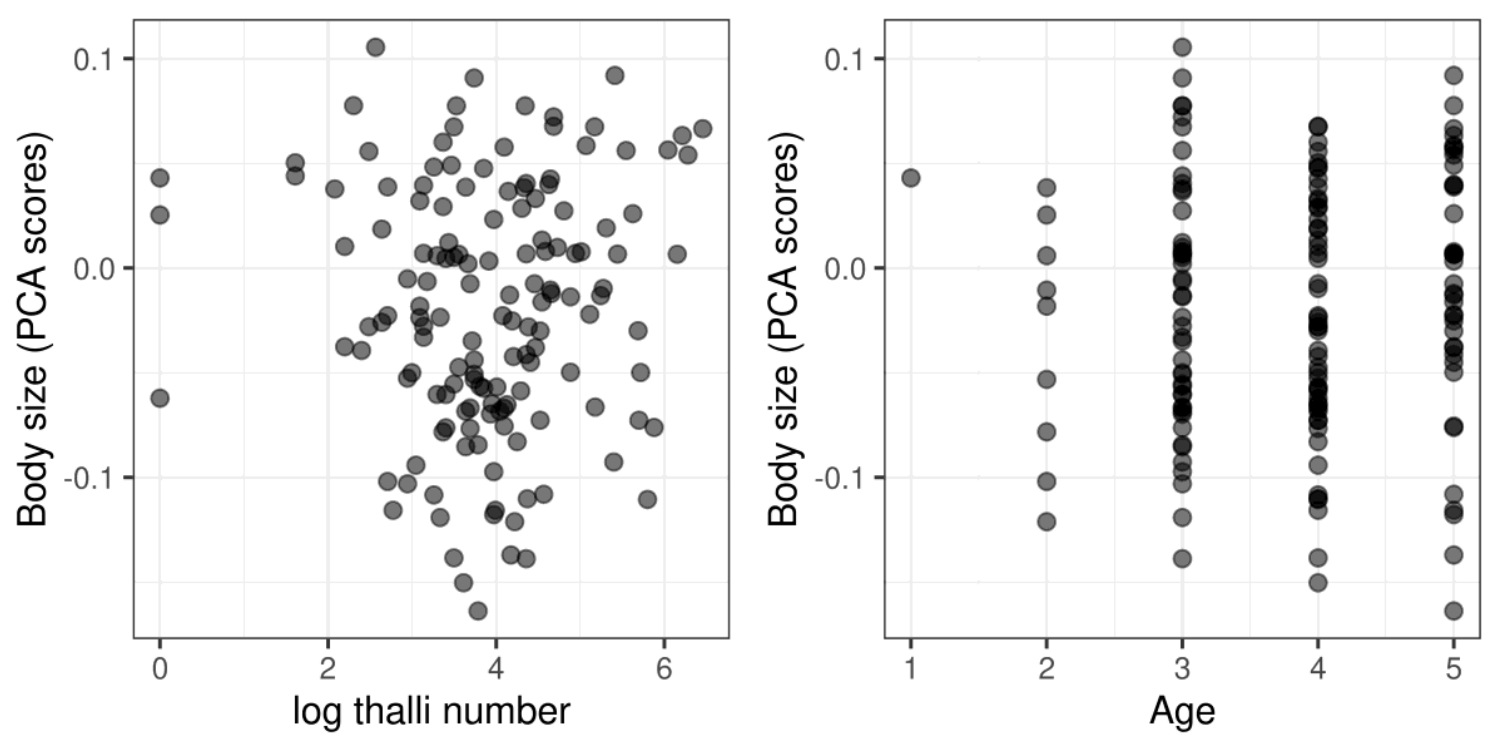

Fig. 2. Visualization of how log-transformed thalli number (left panel) and age (right panel) are associated with body size; based on our LMM neither of them had significant effect on the workers' size. 


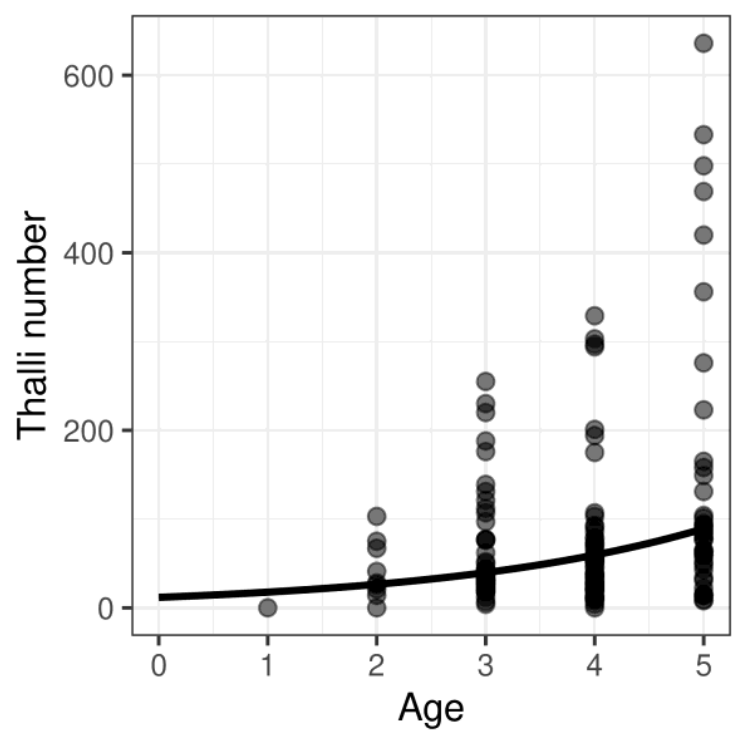

124

Uninfected

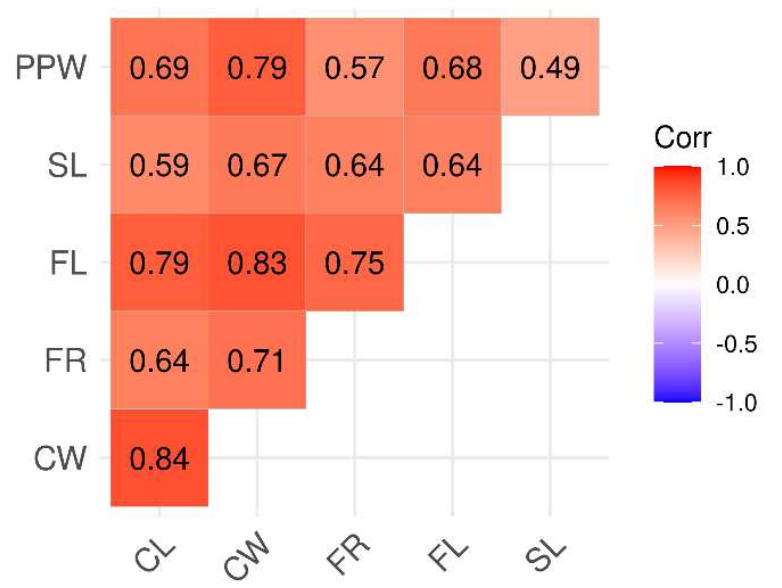

Infected

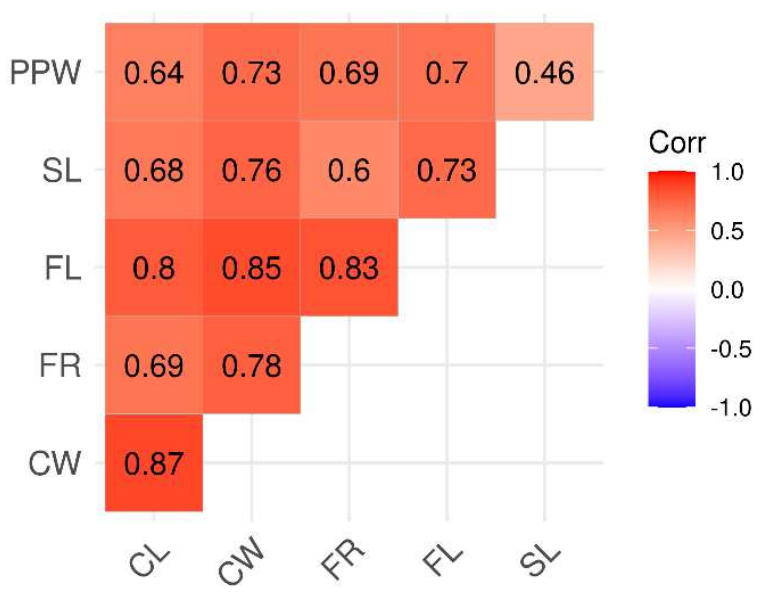

126 Fig. 4. Correlograms visualizing the trait associations of measured body size variables in uninfected (left panel) and infected (right panel) colonies. 
130 Our results show that $R$. wasmannii infected $M$. scabrinodis workers are significantly smaller in a native environment than uninfected ones. This decline in body size in the infected population is consistent across all observed characters. It is important to note that we did not detect shifts in allometries in the characters measured. The significant decrease in size took place synchronously. The lack of shifts in static trait allometries indicates that the size decline in the next generation of workers is not ascribed to physiological stress due to direct larval infections but to a colony-level stress effect caused by widespread infection of $R$. wasmannii fungus across the colonies' adults. Discrete factors, such as parasitism, are known to modify larval development through altered physiological processes, and these developmental perturbations leave their mark on the allometry of some traits of subsequent adults ${ }^{[22]}$, but no traces of such parasitism are detected in natural Myrmica populations. We suppose that a colony-level stress in response to $R$. wasmannii infection is mediated toward larvae by nursing workers, resulting in significantly smaller static trait size among the next generation of their nest mates.

Earlier, laboratory based findings and field studies have shown that this fungal infection does not attack Myrmica larvae ${ }^{[11,21,24,25]}$, but is known to cause an array of detrimental changes in physiology in individual ant workers, such as a decrease in life expectancy, particularly in cases of water and food deprivation ${ }^{[15]}$, increased sanitary behavior ${ }^{[14]}$, and a reduced ability to fight against competitors ${ }^{[16,17]}$. Yet, despite the number of negative effects detected under laboratory conditions, infected colonies in the field have been thought to function relatively well, as they contain queens, larvae and pupae, and all age-classes of workers (see Csata et al. ${ }^{[17]}$ ).

Our research is the first undertaking that provides quantitative evidence concerning a decline in worker size in infected nests, dispelling the previous concept concerning the seeming health of infected colonies and revealing that chronic $R$. wasmannii infection has a long, intergenerational, detrimental colony-level impact in the natural environment.

Infected colonies can somehow manage to compensate for the negative effects of $R$. wasmannii infection (colonies operate with queens, larvae and pupae and they have the capacity to produce sexual forms and maintain their populations), but certain functions are clearly impaired, which is reflected in the decrease in body size among the next generation of workers.

The background of the workers' mediated colony-level stress as a consequence of parasitism is not entirely clear. Similarly to other members of the order Laboulbeniales, $R$. wasmannii does 
not penetrate the cuticle of the host, so the most likely hypothesis concerning the feeding of the parasitic fungus is that it absorbs the necessary nutrients from the workers' cuticle surface or directly from the environment ${ }^{[25]}$. Ants have numerous exocrine glands, the secretions of which are spread on the cuticle surface by self-grooming and allogrooming. This may be confirmed by the fact that infected M. scabrinodis workers show increased sanitary behavior ${ }^{[14]}$. This behavior has been observed in the invasive garden ant (Lasius neglectus van Loon boomsma et Andrásfalvy, 1990) infected by Laboulbenia formicarum Thaxt. ${ }^{[26]}$, where fungus also was not found to penetrate the cuticle of its hosts ${ }^{[25]}$. This increased sanitary behavior could mean that ant workers have less time and energy to care for and feed the brood, which could be another explanation for the decline in body size in subsequence generations in infected colonies.

This might be explained by the discrete, i.e., presence-absence type of stress caused by Rickia infections on colonies, though we do not find this explanation the most persuasive one. The most plausible reason might be lurking in the dynamics and phenology of the infection, namely the level of infection might not correlate with the number of visible thalli on the worker individuals' cuticular surface. We also know that the intensity of infection varies throughout the year, and the peak number of thalli takes place in late autumn ${ }^{[19]}$. This fluctuation, combined with the emergence of smaller workers from the overwintering larvae of Myrmica ants [27], makes it difficult to map the exact processes.

Although only negative effects of the fungus are currently known, we speculate that the increased sanitary behavior may be advantageous against other parasites, and $R$. wasmannii may also have unknown positive effects on its hosts, similar to the . formicarum $^{[14,26]}$.

We also speculate that the decline in size among workers in infected Myrmica ant colonies is part of the colony-level strategy to minimize the adverse effects of the infection in order to mitigate increased mortality and maintain the ability to produce sexuals. From an evolutionary biological perspective, whether a $R$. wasmannii infection impacts the fitness of $M$. scabrinodis colonies is an important question. We do not know whether infected colonies produce smaller or perhaps fewer sexuals or this ultimate function is not impaired. This topic merits further investigation.

\section{Materials and Methods}


Material for the present study was collected from a relatively small, one-acre fragment of a natural marshland surrounded by deciduous, oak-dominated forest near Gyöngyös, Sár-hegy: Gyilkos-rét (23.06.2016; 47.811206, 19.988027; 320 m a.s.1) in Hungary (Fig. 5). This area is part of the Bükk National Park and has not been disturbed or extensively cultivated over the course of the past two decades.
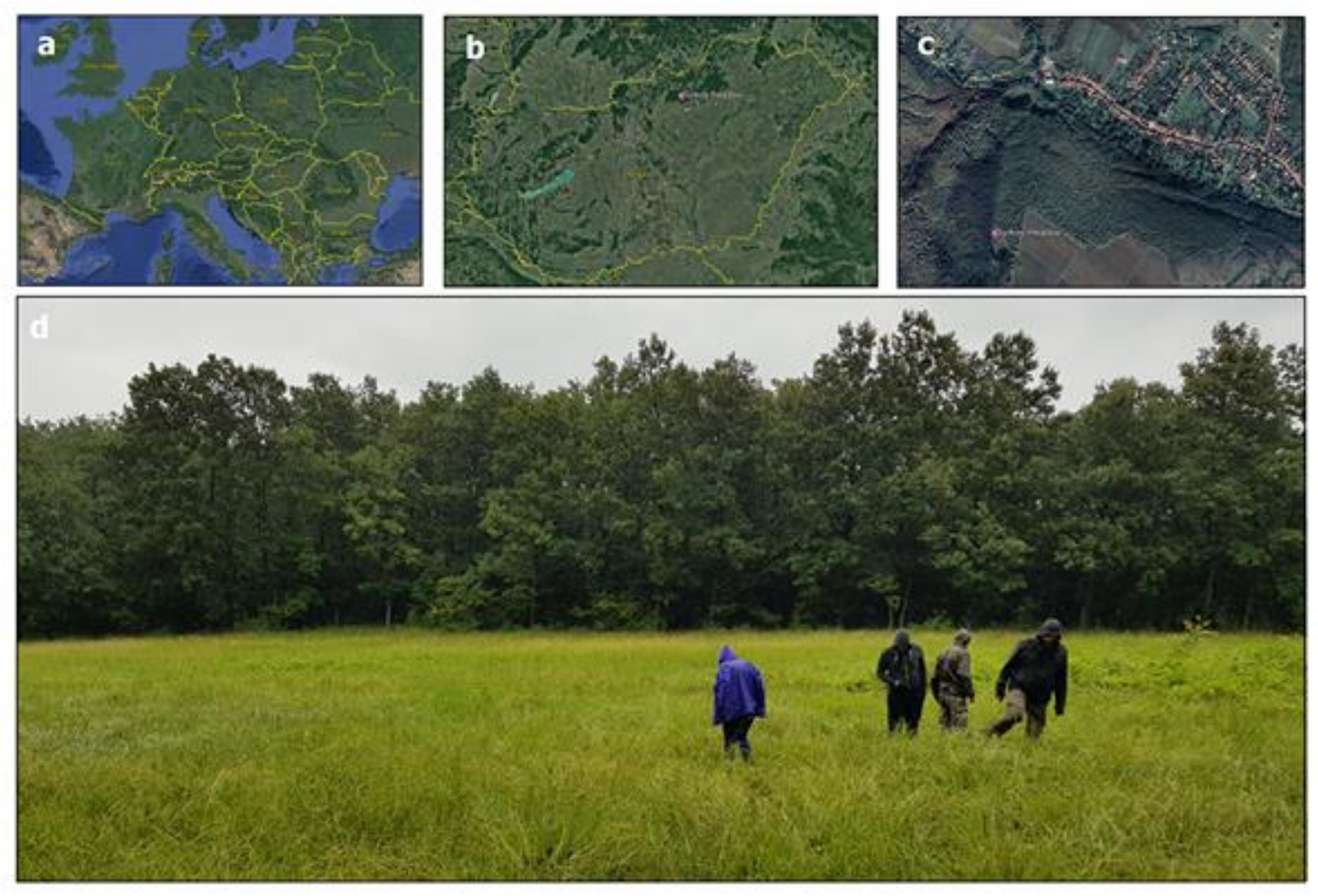

Fig. 5. Field site where M. scabrinodis workers for our study were collected. Field site is located in Europe (a), Hungary (b) near Pálosvörösmart (c). Wet meadow (Gyilkos-rét) surrounded by deciduous forest (d).

\section{Sampling}

Infected (Fig. 6) and uninfected M. scabrinodis colonies were found via hand searching in the grassland by FB and AT. Sampling activities were concentrated in a short, one-day period of time (23.06.2016) because $R$. wasmannii infection is known to show seasonal fluctuation ${ }^{[19]}$. Altogether 30 M. scabrinodis colonies were used as samples, and 15 uninfected and 15 infected specimens were taken from each colony. The nests were carefully opened and the presence of 
$R$. wasmannii on the workers' body surfaces was checked in every colony with the use of a 40x magnifying glass in the field. After inspection, a small fragment of colony workers was collected from each nest. The sampled workers were stored in $1.5 \mathrm{~mL}$ Eppendorf tubes with $67.5 \%$ EtOH until observation in the laboratory.

\section{Thallus number on the workers' cuticular surfaces}

Altogether, 225 M. scabrinodis workers (15 individuals from each infected colony) were screened (by FB) for fungal thalli (Fig. 6). All fungal thalli on the whole ant body were counted using a Leica MZ125 stereomicroscope at $\times 10-160$ magnification as described by Báthori et al. ${ }^{[20]}$. After the fungal thalli had been counted, colony infection level was calculated based on arithmetic mean thalli number of 15 randomly sampled workers from each colony.

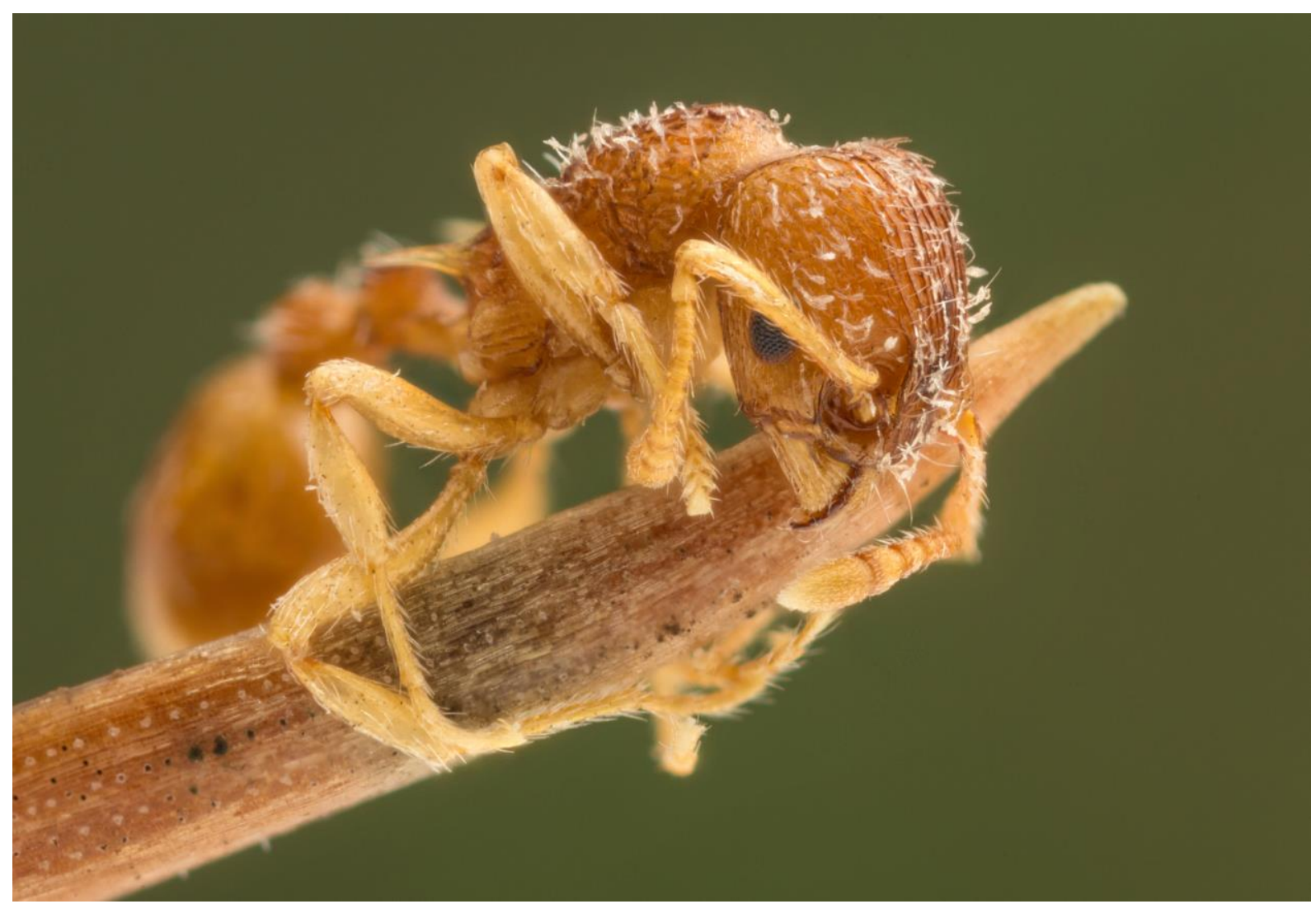

Fig. 6. Habitus image of an infected Myrmica scabrinodis worker. Rickia wasmannii thalli cover the head, mesosoma, and, to a lesser extent, the appendages. Photo: Zsolt Újvári. 
As was done by Báthori et al. ${ }^{[20]}$, all infected M. scabrinodis workers screened for fungal thalli were separated into different age groups. Based on the degree of cuticular pigmentation, five different age categories were described by Cammaerts-Tricot ${ }^{[28]}$. The infected individuals were classified into categories according to cuticle coloration from younger to older (1-5). The highly pigmented oldest workers were given the highest numbers.

\section{Morphometric character recording}

The measured morphometric characters are defined as in ${ }^{[22]}$. The measurements of altogether 300 M. scabrinodis workers (10 from each colony) were made with an ocular micrometer using a Leica MZ125 stereomicroscope at a magnification of $\times 50$ for CL, CW and FR, $\times 100$ for FL, SL and PPW (all measurements were recorded in $\mu \mathrm{m}$ ). All measurements were made by FB. Measured characters are defined in Table 1. Raw data are available in Supplementary table 1.

\section{Measurement error assessment}

All measurements are subject to error, therefore repeatability, i.e., the degree of agreement between pairs of observations made on the same measurand under the same conditions, i.e. made by the same observer, using the same microscope, following the same measurement protocol as defined in Csősz et al. ${ }^{[29]}$, was tested before the statistic framework was created. The repeatability of the recorded size parameters was assessed via Intraclass Correlation Coefficients (ICC) on repeated measurements of 16 ant specimens using Package ICC (Wolak et al. 2012). ICC scores are given for each characteristic in Table 1.

\begin{tabular}{|l|l|l|}
\hline Abbr. & Description of traits & ICC \\
\hline CL & $\begin{array}{l}\text { Cephalic length measured from the anterior-most point of } \\
\text { clypeal margin to the mid-point of the occipital margin, } \\
\text { in full-face view. }\end{array}$ & $0.990 \quad[0.980,1.000]$ \\
\hline $\mathrm{CW}$ & $\begin{array}{l}\text { Cephalic width measured in full-face view, including } \\
\text { compound eyes. }\end{array}$ & $0.997 \quad[0.994,1.000]$ \\
\hline
\end{tabular}




\begin{tabular}{|l|l|l|}
\hline FR & $\begin{array}{l}\text { Frons width measured according to the minimum } \\
\text { distance between the frontal carinae. }\end{array}$ & $0.995 \quad[0.990,1.000]$ \\
\hline FL & $\begin{array}{l}\text { Frontal lobe width measured according to the maximum } \\
\text { distance between external borders of the frontal lobes. }\end{array}$ & $0.995 \quad[0.991,1.000]$ \\
\hline SL & $\begin{array}{l}\text { Scape length measured from the neck to the distal end of } \\
\text { the scape. }\end{array}$ & $0.993 \quad[0.986,1.000]$ \\
\hline PPW & $\begin{array}{l}\text { Postpetiole width measured according to the maximum } \\
\text { width of the postpetiole in dorsal view. }\end{array}$ & $0.996 \quad[0.991,1.000]$ \\
\hline
\end{tabular}

Table 1. Verbatim trait definitions for morphometric character recording. Abbreviation (Abbr.), verbatim character definition and intraclass correlation coefficients (ICC) of certain morphometric traits are provided. Upper and lower bounds of ICC scores, separated by a coma, are also given in parentheses.

\section{Statistical analysis}

All data analyses were performed with $\mathrm{R}$ version 4.0.2. ${ }^{[30]}$. To reduce the number of variables on body size we used principal component analysis (PCA) by non-linear iterative partial least squares (NIPALS) with the R-package "nipals" [31]. We preferred this method over classical PCA because in a small number of cases ( 7 in total) size measurements of some body parts for a given ant were not feasible (hence the missing measurements); NIPALS can use data with missing observations, whereas in classical PCA we should have excluded all those specimens for which any measurement was missing. Variables were centered at zero (by subtracting variable mean from each value) and rescaled (by dividing all values by the variable standard deviation) in order to bring them to the same scale. We retained only the first PCA axis (being the only axis with an eigen-value higher than 1), which corresponded to $77 \%$ of the total variation in the six body measurement variables and was positively correlated with all variables. 
266 To test whether there is a significant difference in body size between infected and uninfected 267 colonies, we used a mixed-effects linear regression model (LMM) with Gaussian error 268 distribution using the R-packages "lme4" and "lmerTest" [32,33], specifying the abovementioned 269 PCA axis representing body size as the dependent variable and infection as independent factor. 270 To test how the severity of fungal infection and age affected body size, we fitted another LMM 271 (naturally, only using data from infected colonies) with the body size PCA axis as a dependent 272 variable and the log-transformed number of thalli and age as independent variables. Because 273 previously it had been shown that age and thalli number can be correlated, we estimated 274 variance inflation factors to see whether there is substantial multicollinearity between the 275 independent variables used and the "car" package ${ }^{[34]}$. In addition, we tested the association 276 between age and thalli number using a Poisson generalized LMM (GLMM), specifying thalli 277 number as a dependent variable. In both LMMs and in the GLMM, colony number was used as 278 a random effect to control for the non-independence of observations from the same colonies.

279 Furthermore, to see whether the infection causes changes in static trait allometries across the measured body size indices, we estimated trait correlations (Pearson's $\rho$ ) separately for uninfected and infected colonies and compared the resulting two correlation matrices ${ }^{[35]}$. 


\section{References}

284

285

286

287

288

289

290

291

292

293

294

295

296

297

298

299

300

301

302

303

304

305

306

307

1. Valles, S. M. et al. A picorna-like virus from the red imported fire ant, Solenopsis invicta: initial discovery, genome sequence, and characterization. Virology, 328(1), 151-157. doi: 10.1016/j.virol.2004.07.016 (2004).

2. Russell, J. A. The ants (Hymenoptera: Formicidae) are unique and enigmatic hosts of prevalent Wolbachia (Alphaproteobacteria) symbionts. Myrmecol. News, 16, 7-23. (2012).

3. Mongkolsamrit, S. et al. Life cycle, host range and temporal variation of Ophiocordyceps unilateralis/Hirsutella formicarum on Formicine ants. J. Invertebr. Pathol. 111(3), 217-224. doi: 10.1016/j.jip.2012.08.007 (2012).

4. Espadaler, X. \& Santamaria, S. Ecto-and endoparasitic fungi on ants from the Holarctic region. Psyche 2012. doi: 10.1155/2012/168478 (2012).

5. Hughes, W. O. H. Life histories and parasite pressure across the major groups of social insects. Insect. Evol. Ecol. Proc. R. Entomol. Soc, 211, 139. (2005).

6. Lachaud, J. P., Lenoir, A. \& Hughes, D. P. Ants and their parasites Psyche 2013, doi: $10.1155 / 2013 / 264279$ (2013). 
8. Witek, M., Barbero, F. \& Markó, B. Myrmica ants host highly diverse parasitic communities: from social parasites to microbes. Insect. Soc. 61(4), 307-323. doi: 10.1007/s00040-014-03626 (2014).

9. Tartally, A., Szücs, B. \& Ebsen, J. R. The first records of Rickia wasmannii Cavara, 1899, a myrmecophilous fungus, and its Myrmica Latreille, 1804 host ants in Hungary and Romania (Ascomycetes: Laboulbeniales, Hymenoptera: Formicidae). Myrmecol. News, 10, 123. (2007).

10. García, F., Espadaler, X., Echave, P. \& Vila, R. Hormigas (Hymenoptera, Formicidae) de los acantilados de l'Avenc de Tavertet (Barcelona, Península Ibérica). Boletín de la Sociedad entomológica Aragonesa, 47, 363-367. (2010).

11. Bezděčková, K. \& Bezděčka P. First records of the myrmecophilous fungus Rickia wasmannii (Ascomycetes: Laboulbeniales) in the Czech Republic. Acta Musei Moraviae Scientiae biologicae, 96.1: 193-197. (2011).

12. Cavara, F. Di una nuova Laboulbeniacea: Rickia wasmannii, nov.gen. e nov.spec. Malpighia 13, 173-188. (1899).

13. Hulden, L. Floristic notes on palaearctic Laboulbeniales (Ascomycetes). Karstenia 25, 116. (1985).

\section{Csata, E., Erős, K. \& Markó, B. Effects of the ectoparasitic fungus Rickia wasmannii on its} ant host Myrmica scabrinodis: changes in host mortality and behavior. Insect. Soc. 61(3), 247252. doi: 10.1007/s00040-014-0349-3 (2014). 
15. Báthori, F., Csata, E. \& Tartally, A. Rickia wasmannii increases the need for water in Myrmica scabrinodis (Ascomycota: Laboulbeniales; Hymenoptera: Formicidae). J. Invertebr. Pathol. 126, 78-82. doi: 10.1016/j.jip.2015.01.005 (2015).

16. Báthori, F., Rádai, Z. \& Tartally, A. The effect of Rickia wasmannii (Ascomycota, Laboulbeniales) on the aggression and boldness of Myrmica scabrinodis (Hymenoptera, Formicidae). J. Hymenopt. Res. 58, 41. doi: 10.3897/jhr.58.13253 (2017).

17. Csata, E. et al. Lock-picks: fungal infection facilitates the intrusion of strangers into ant colonies. Sci. Rep-UK., 7(1), 1-14. doi: 10.1038/srep46323 (2017).

18. Tartally, A. et al. Patterns of host use by brood parasitic Maculinea butterflies across Europe. Philos. T. Roy. Soc. B. 374(1769), 20180202. doi: 10.1098/rstb.2018.0202 (2019).

19. Haelewaters, D., Boer, P., Gort, G. \& Noordijk, J. Studies of Laboulbeniales (Fungi, Ascomycota) on Myrmica ants (II): variation of infection by Rickia wasmannii over habitats and time. Anim. Biol. 65(3-4), 219-231. doi: 10.1163/15707563-00002472 (2015).

20. Báthori, F., Pfliegler, W. P., Rádai, Z. \& Tartally, A. Host age determines parasite load of Laboulbeniales fungi infecting ants: implications for host-parasite relationship and fungal life history. Mycoscience, 30, 1e6. doi: 10.1016/j.myc.2017.09.004 (2017).

21. Bezděčka, P. \& Bezděčková, K. First record of the myrmecophilous fungus Rickia wasmannii (Ascomycetes: Laboulbeniales) in Slovakia. Folia Faunistica Slovaca, 16(2), 7172. (2011).

22. Csősz, S. \& Majoros, G. Ontogenetic origin of mermithogenic Myrmica phenotypes (Hymenoptera, Formicidae). Insect. Soc. 56, 70-76 doi: 10.1007/s00040-008-1040-3 (2009). 
364

365

366

367

368

369

370

371

372

373

374

375

376

377

378

379

380

381

382

383

384

385

386

387

388

23. Di Salvo, M. et al. The microbiome of the Maculinea-Myrmica host-parasite interaction. Sci. Rep-UK. 9(1), 1-10. doi: 10.1038/s41598-019-44514-7 (2019).

24. Pfliegler, W. P., Báthori, F., Haelewaters, D. \& Tartally, A. Studies of Laboulbeniales on Myrmica ants (III): myrmecophilous arthropods as alternative hosts of Rickia wasmannii. Parasite, 23, 50. doi: 10.1051/parasite/2016060 (2016).

25. Tragust, S., Tartally, A., Espadaler, X. \& Billen, J. Histopathology of Laboulbeniales (Ascomycota: Laboulbeniales): ectoparasitic fungi on ants (Hymenoptera: Formicidae). Myrmecol. News, 23, 81-89. doi: 10.25849/myrmecol.news_023:081 (2016).

26. Konrad, M., Grasse, A. V., Tragust, S. \& Cremer, S. Anti-pathogen protection versus survival costs mediated by an ectosymbiont in an ant host. P. Roy. Soc. B-Biol. Sci. 282(1799), 20141976. doi: 10.1098/rspb.2014.1976 (2015).

27. Brian, M.V. Summer population changes in colonies of the ant Myrmica. Physiol. Comp. Oecol. 2, 248-262. (1951).

28. Cammaerts-Tricot, M. C. Production and perception of attractive pheromones by differently aged workers of Myrmica rubra (Hymenoptera Formicidae). Insect. Soc. 21(3), 235-247. doi: 10.1007/BF02226916 (1974).

29. Csősz, S. et al. Insect morphometry is reproducible under average investigation standards. Ecology and evolution, 11(1), 547-559. doi: 10.1002/ece3.7075 (2020). 
30. R Core Team. R: A language and environment for statistical computing. R Foundation for 390 Statistical Computing, Vienna, Austria. URL https://www.R-project.org/. R version 4.0.2 391 (2020-06-22) (2020).

392

31. Wright, K. nipals: Principal Components Analysis using NIPALS or Weighted EMPCA, 394 with Gram-Schmidt Orthogonalization. $\mathrm{R}$ package version 0.7. https://CRAN.R395 project.org/package $=$ nipals $(2020)$

396

397

398

32. Bates, D., Mächler, M., Bolker, B. \& Walker, S. Fitting linear mixed-effects models using lme4. arXiv preprint arXiv:1406.5823. (2014).

399

400

401

33. Kuznetsova, A., Brockhoff, P. B. \& Christensen, R. H. lmerTest package: tests in linear mixed effects models. J. Stat. Soft. 82(13), 1-26. doi: 10.18637/JSS.V082.I13 (2017).

402

403

404

34. Fox, J. \& Weisberg, S. An R Companion to Applied Regression, 3rd edition. Sage, Thousand Oaks CA. (2019).

405

406

35. Jennrich, R. I. An asymptotic $\chi^{2}$ test for the equality of two correlation matrices. J. Am.

407

Stat. Assoc. 65(330), 904-912. doi: 10.1080/01621459.1970.10481133 (1970).

408

409 
411 This research was supported by the 'AntLab' Marie Curie Career Integration Grant (to AT), 412 part of the 7th European Community Framework Programme, and National Research, 413 Development, and Innovation Fund under Grant No. K 135795 (S.C). AT was supported by a 414 'János Bolyai' Scholarship of the Hungarian Academy of Sciences, by the EFOP-3.6.1-16415 2016-00022 project (co-financed by the European Union and the European Social Fund) and 416 by the ÚNKP-20-5 New National Excellence Program of the Ministry of Human Capacities.

417

418 Author contributions

419 SC and FB contributed to the study conception and design. Data preparation, data collection 420 was performed by FB, LEB. Data analyses were performed by SC and ZR. The first draft of the 421 manuscript was written by SC, FB and AT and all authors commented on previous versions of 422 the manuscript. All authors read and approved the final manuscript.

423

424

Data availability

425 Raw data are available from the Supplementary table 1.

427 Additional Information

428 The authors declare that there is no conflict of financial and non-financial interest. 
Figures

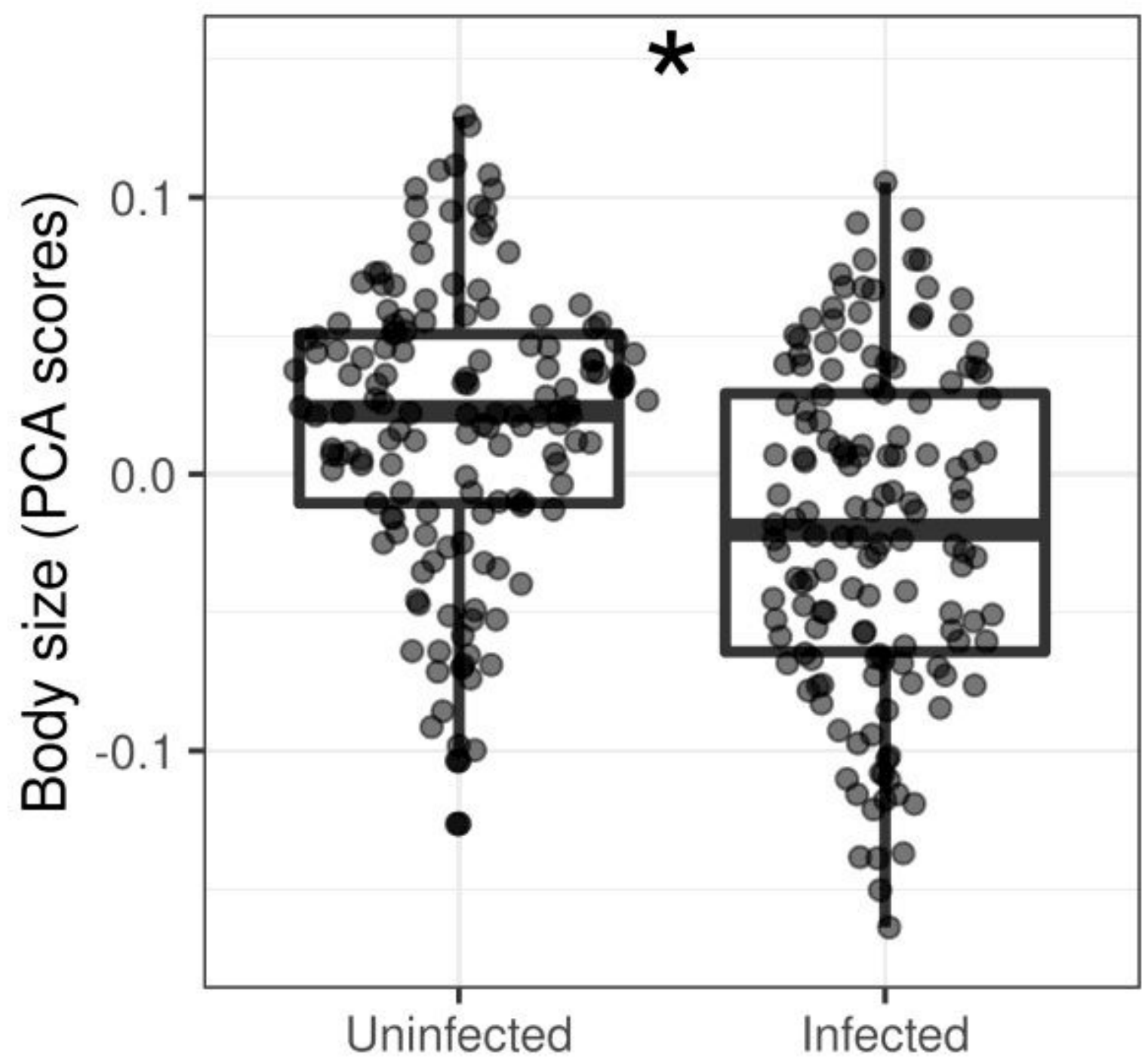

Figure 1

Distribution of PCA axis values representing body size in uninfected and infected colonies. Asterisk marks statistically significant difference. 

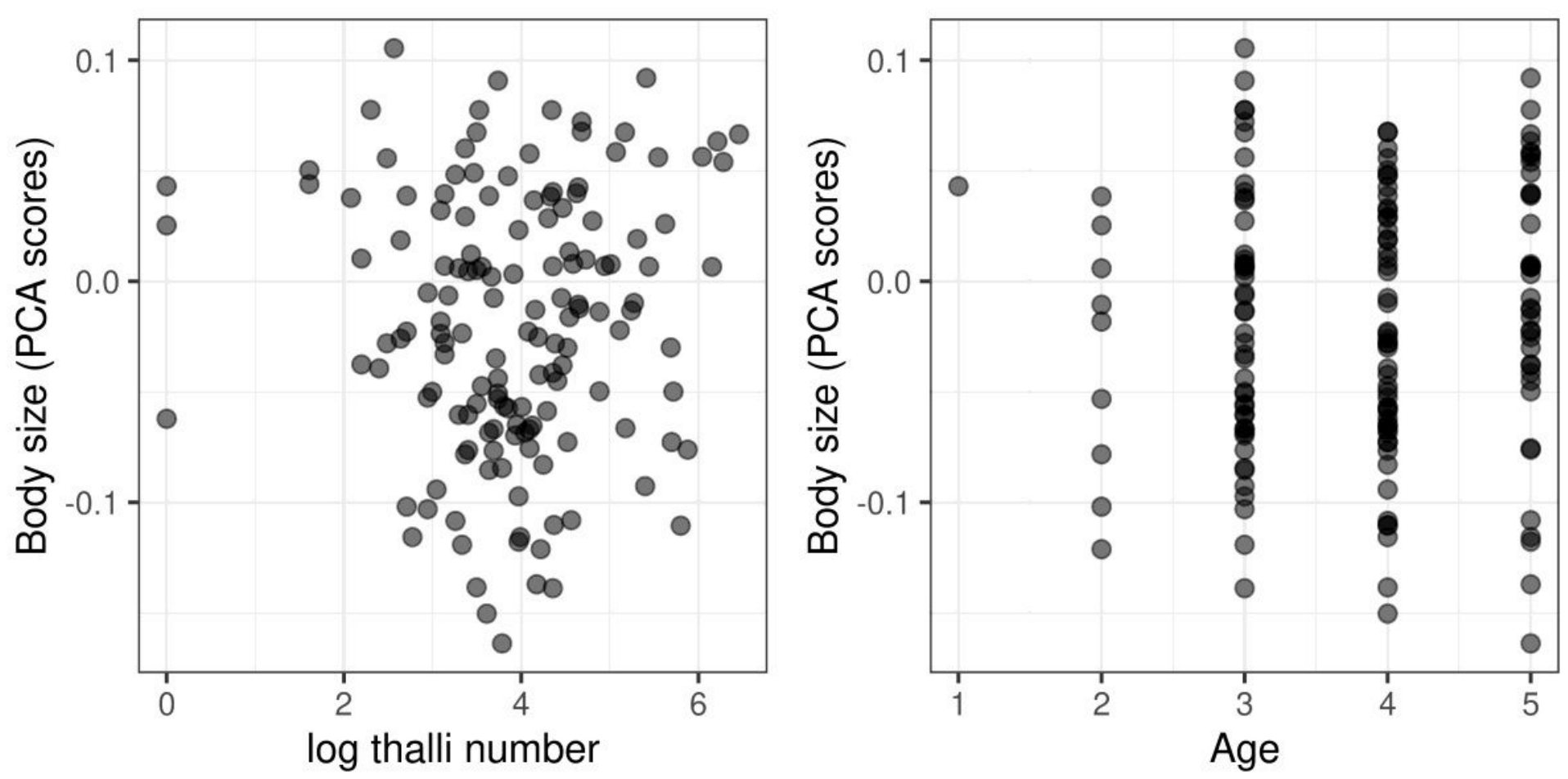

Figure 2

Visualization of how log-transformed thalli number (left panel) and age (right panel) are associated with body size; based on our LMM neither of them had significant effect on the workers' size. 


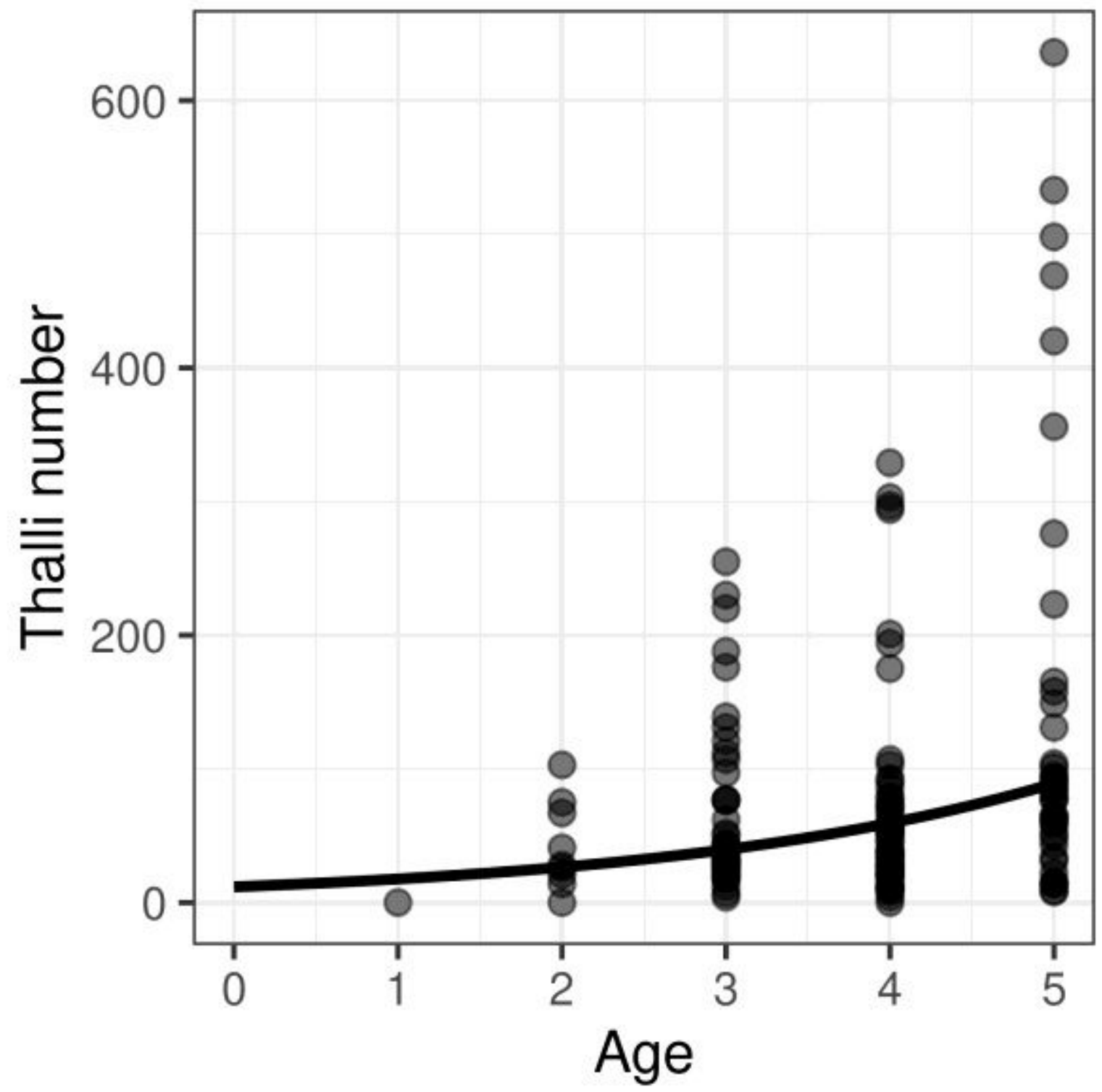

Figure 3

Association of age and thalli number of workers among infected colonies. The solid line represents the association predicted on the Poisson GLMM. 
Uninfected

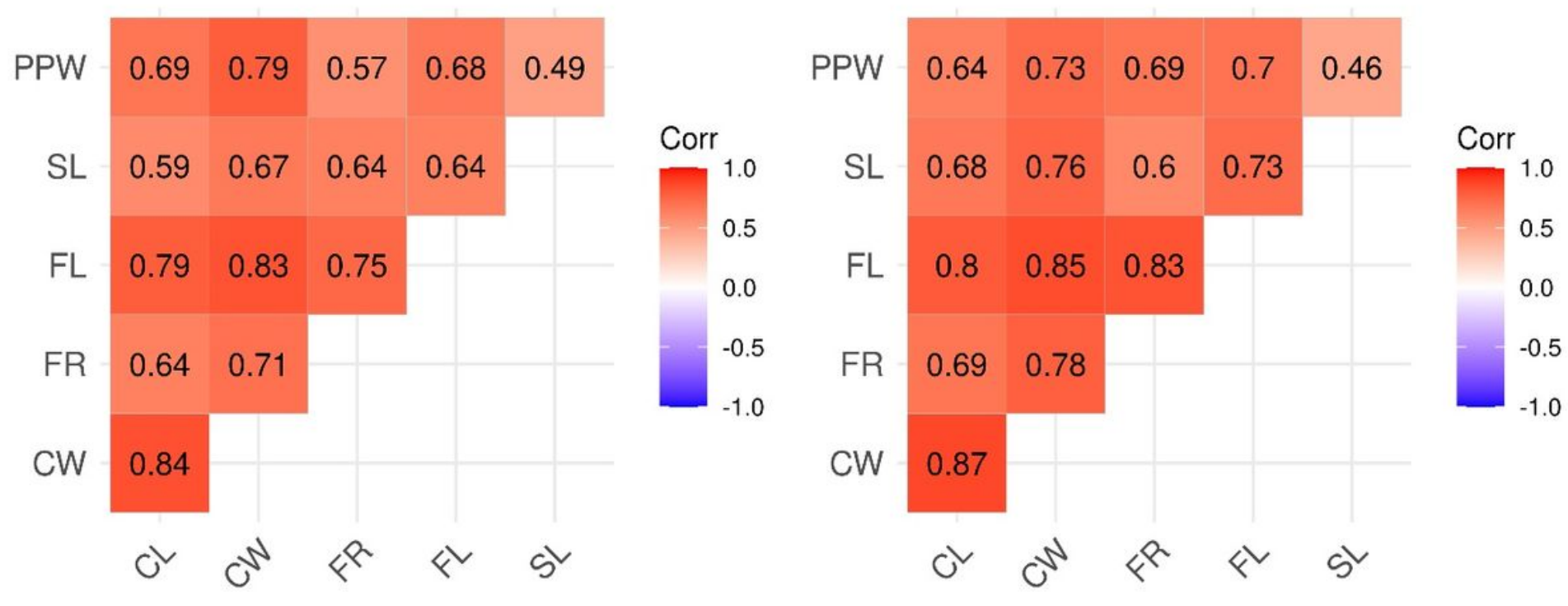

Figure 4

Correlograms visualizing the trait associations of measured body size variables in uninfected (left panel) and infected (right panel) colonies.

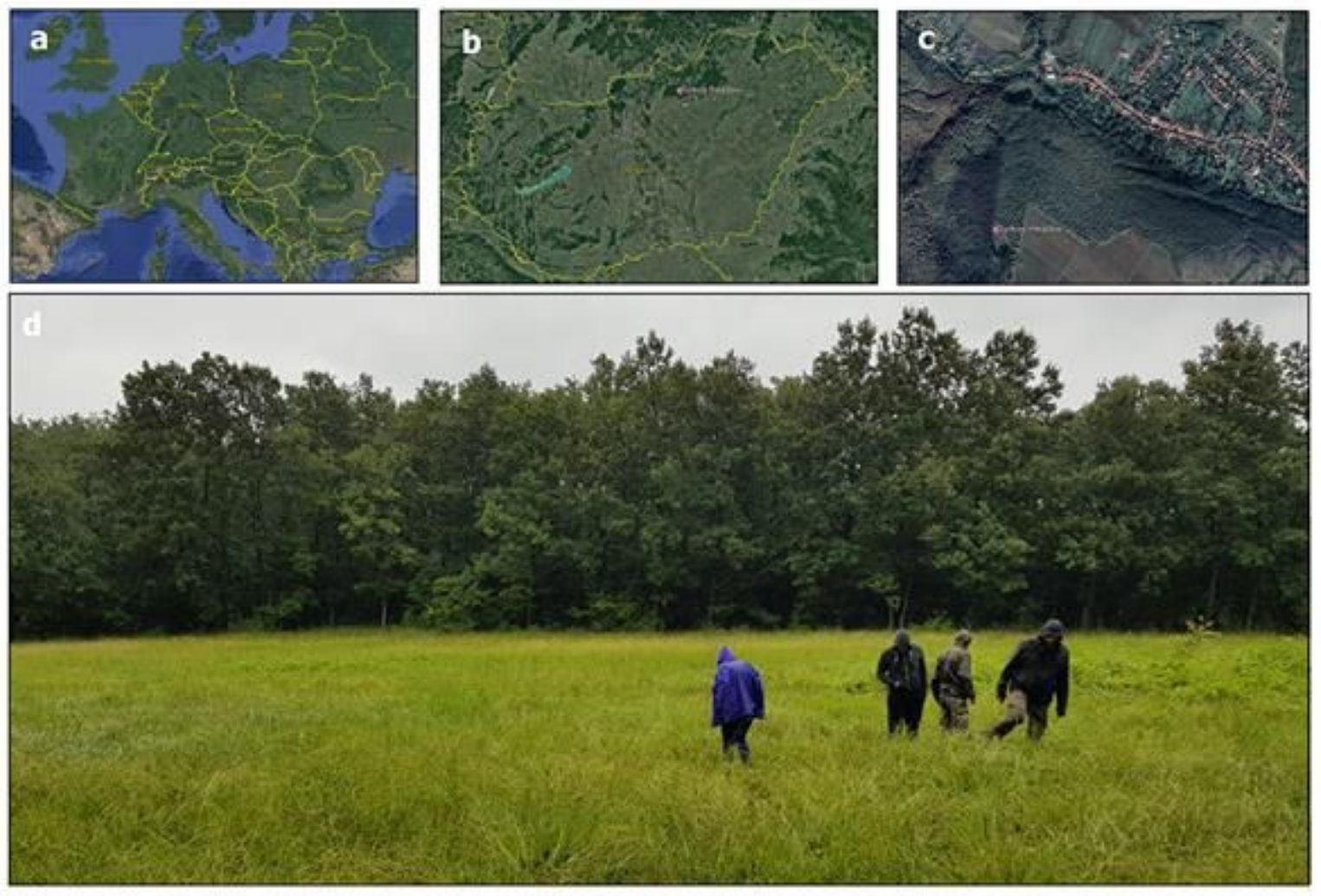

Figure 5 
Field site where M. scabrinodis workers for our study were collected. Field site is located in Europe (a), Hungary (b) near Pálosvörösmart (c). Wet meadow (Gyilkos-rét) surrounded by deciduous forest (d).

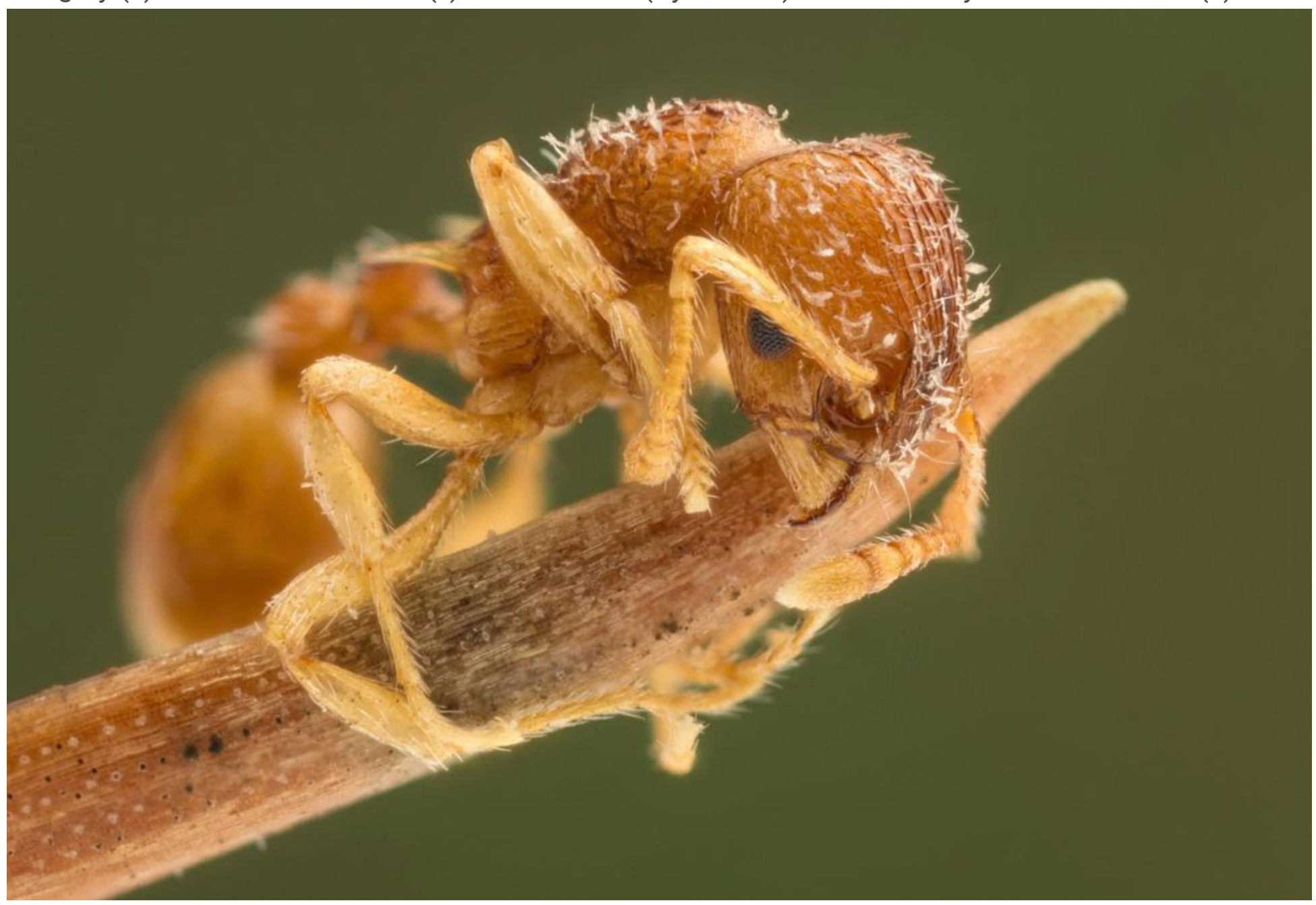

\section{Figure 6}

Habitus image of an infected Myrmica scabrinodis worker. Rickia wasmannii thalli cover the head, mesosoma, and, to a lesser extent, the appendages. Photo: Zsolt Újvári.

\section{Supplementary Files}

This is a list of supplementary files associated with this preprint. Click to download.

- SupplementaryTable1.xlsx 